\title{
Ecological Water Stress under Projected Climate Change across Hydroclimate Gradients in the North-Central United States
}

\author{
ARJUN ADHIKARI ${ }^{\mathrm{a}}$ AND ANDREW J. HANSEN \\ Department of Ecology, Montana State University, Bozeman, Montana \\ IMTIAZ RANGWALA \\ North Central Climate Adaptation Science Center, Cooperative Institute for Research in Environmental Sciences, \\ University of Colorado Boulder, Boulder, Colorado
}

(Manuscript received 29 June 2018, in final form 26 July 2019)

\begin{abstract}
Water balance influences the distribution, abundance, and diversity of plant species across Earth's terrestrial system. In this study, we examine changes in the water balance and, consequently, the dryland extent across eight ecoregions of the north-central United States by quantifying changes in the growing season (May-September) moisture index (MI) by 2071-99, relative to 1980-2005, under three high-resolution $(\sim 4 \mathrm{~km})$ downscaled climate projections (CNRM-CM5, CCSM4, and IPSL-CM5A-MR) of high-emission scenarios (RCP8.5). We find that all ecoregions are projected to become drier as based on significant decreases in MI, except four ecoregions under CNRM-CM5, which projects relatively more moderate warming and much greater increases in precipitation relative to the other two projections. The mean projected MI across the entire study area changes by from $+4 \%$ to $-33 \%$. The proportion of dryland (MI $<0.65$ ) is projected to increase under all projections, but more significantly under the warmer and drier projections represented by CCSM4 and IPSL-CM5A-MR; these two projections also show the largest spatial increases in the arid $(33 \%-53 \%)$ and hyperarid $(135 \%-180 \%)$ dryland classes and the greatest decrease in the dry subhumid (from $-56 \%$ to $-88 \%$ ) dryland class. Among the ecoregions, those in the semiarid class have the highest increase in potential evapotranspiration, those in the nondryland and dry subhumid class have the largest decrease in MI, and those in the dry subhumid class have the greatest increase in dryland extent. These changes are expected to have important implications for agriculture, ecological function, biodiversity, vegetation dynamics, and hydrological budget.
\end{abstract}

\section{Introduction}

Water balance on the landscape influences the distribution, abundance, and diversity of plant species across Earth's climate gradients (Fisher et al. 2011; Bond and Bumbaco 2015). It is often estimated as the ratio between precipitation (PPT) and potential evapotranspiration (PET) and referred to as the moisture or aridity index (hereinafter MI) (Rind et al. 1990). The MI indicates either a potential surplus or deficit of available

\footnotetext{
${ }^{\text {a }}$ Current affiliation: Department of Natural Resource Ecology and Management, Oklahoma State University, Stillwater, Oklahoma.
}

\footnotetext{
Corresponding author: Arjun Adhikari, arjun.adhikari@okstate. edu
}

surface water content in a given environment and can be used to characterize, for example, spatial extent of drylands (defined as MI $<0.65$ ) at subcontinental scale (Tereshchenko et al. 2015). Across many regions of the globe, increased temperatures from anthropogenic global warming have increased PET and reduced MI (Feng and Fu 2013). This situation has posed significant impacts to regional and global hydrological cycles, ecological processes, vegetation growth, and water balance (Feng and Fu 2013; Clark et al. 2016; Hobbins et al. 2016; Adhikari and Hansen 2019). Because there are several formulations of PET including PenmanMonteith (Penman 1948; Monteith 1965), Thornthwaite (1948), Priestley and Taylor (1972), and Turc (1961), MI results based on these methods can differ substantially. In this paper, we assess the historical and projected spatial patterns of PET and MI based on 
TABLE 1. Dryland classes as defined by the ratio of precipitation to evapotranspiration, and their ecological potential.

\begin{tabular}{lcc}
\hline Dryland class & MI range & Characteristics \\
\hline Dry subhumid & $0.5<\mathrm{MI}<0.65$ & $\begin{array}{c}\text { Low interannual variability in rainfall; highly exposed to drought; intensive land use for } \\
\text { agriculture and grazing } \\
\text { High interannual variability in rainfall, with 250-450 mm; includes steppe, dry savannas, } \\
\text { and tropical scrublands; occasional rain-fed agriculture is possible } \\
\text { Annual precipitation ranges from 200 to 350 mm; includes areas with bushes and small } \\
\text { woody and leafless shrubs; agriculture is not possible }\end{array}$ \\
Arid & $0.2<\mathrm{MI}<0.5$ & $\begin{array}{c}\text { Highly variable rainfall; does not support perennial vegetation but annual may be } \\
\text { present; grazing and agriculture are impossible }\end{array}$ \\
\hline
\end{tabular}

physically robust Penman-Monteith (PM) PET estimation and discuss their potential impacts across waterbalance ecotones of the north-central United States (hereinafter NCUS).

The evaporative demand of the atmosphere is often expressed in terms of PET, which is defined as the amount of evapotranspiration that would occur from a surface in presence of sufficient water and optimal plant development (e.g., Rind et al. 1990). Projected atmospheric warming is expected to increase evaporative demand on arid and semiarid regions and impose strong constraints on plant growth where increasing precipitation cannot offset this increasing rate of evapotranspiration (Hanson 1991; Clark et al. 2016). Thus, there is high interest in assessing likely consequences of projected changes in PET and indicators of water availability derived from it for the hydrological cycle, crop growth, and vegetation dynamics across a regional scale (Hatch et al. 1999; Feng and Fu 2013; Hobbins et al. 2016).

Because of the ecological importance of PET and its implications for the water budget, recent studies have focused on further evaluating the methods and spatial scales to quantify PET (van der Schrier et al. 2011; King et al. 2015; Dewes et al. 2017). Studies projecting effects of climate change on PET and MI at fine scales have used the more simplistic Thornthwaite-type methods because the input variable - temperature - is available at fine scales (McKenney and Rosenberg 1993; Hobbins et al. 2008; van der Schrier et al. 2011). Applications of the more realistic Penman method have been restricted to relatively coarse scales (e.g., $60 \mathrm{~km}$ ), largely because the key parameters have not been available at finer resolutions (Dewes et al. 2017). As management decisions are made at local to regional scales and strong differences in climate exist across these scales, there is a need to know how MI is likely change in the future under a robust method.

Of particular concern is the effect of climate change on dryland regions. Drylands are the zones where MI ranges from 0.05 to 0.65 (UNCCD 1994; Feng and Fu 2013). Four classes of drylands are recognized, each with different potential for ecology and agriculture (Table 1). These classes can be used as quantitative indicators of differences and changes in water availability and its consequences for a given region. A warming climate along with unsustainable land-use practices always puts these lands at the risk of desertification (Reynolds et al. 2007). Therefore, quantifying changes in MI across environmental gradients under a changing climate will help us to better understand the extent of aridification in different dryland zones and assess its impacts on biodiversity, ecological process, and agriculture sustainability.

Drylands are extremely important for agriculture output as they occupy $41 \%$ of global land and support $38 \%$ of the global human population (Millennium Ecosystem Assessment 2005; Reynolds et al. 2007). Yet drylands have been found most vulnerable to climate change and land-use simplification due to human exploitation of limited natural resources (Vogt et al. 2011; Adhikari et al.2019). Many parts of the world have been projected to experience increased aridity, heat, water shortage, and productivity decline (Feng and Fu 2013). Past studies indicated that drylands become drier under increasing global warming (IPCC 2013; Zarch et al. 2017). Given that temperature, humidity, solar radiation, and wind speed vary across topographic gradients in regional landscapes, it is expected that the spatial patterns of dryland zones based on MI differ across the region. Consequently, assessment of drylands on a regional scale is necessary to assess the landscape characteristics for adaptation at the forefront of water scarcity. There are currently no analyses of how spatial patterns of drylands vary under climate change across strong water-balance ecotones ranging from high humid to highly dry ecoregions, such as exist across the NCUS.

The goal of this paper is to quantify and to characterize projected changes in surface water availability through MI across the topographic and climate gradients of the NCUS at spatial scales $(4 \mathrm{~km})$ that are relevant to management. We use the physically robust Penman method to characterize the range of changes 


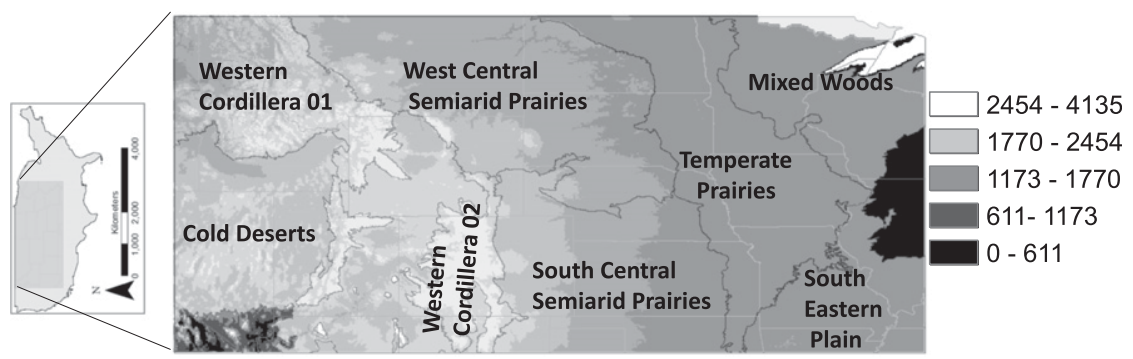

FIG. 1. Elevation map (m MSL) of the study region in the NCUS. EPA Level II ecoregions are outlined in gray (Danielson and Gesch 2011).

in MI under three climate projections. In addition, we evaluate changes in the spatial extent of dryland classes under these climate projections based on MI derived from Penman PET. The specific objectives of our study are 1) to assess the degree of projected change in MI under future climate projections across different environmental gradients at managementrelevant spatial scales and 2) to evaluate the changes in dryland classes under future climate projections across the study region.

\section{Materials and methods}

\section{a. Study area}

Our study focuses on the NCUS, spanning from the Rocky Mountains to the Mississippi Valley and including the Great Plains, tall grass prairie, and parts of the Ozark Plateau (Fig. 1). The eight EPA Level II ecoregions in the study area vary substantially in topography, climate, and vegetation (Table 2). The western cordillera ecoregions are mountainous, with differences in temperature and precipitation that are generated by strong elevation gradients. The higher elevations have relatively high precipitation that falls mainly as snow while valley bottoms are relatively warm and dry. Conifer forests dominate the mountains, while grasslands and shrublands cover the valley bottoms. We divided the western cordillera ecoregion into two ecoregions (western cordillera 01 and western cordillera 02) since the two units are spatially disjunct. The cold deserts ecoregion is largely a high dissected plateau with cold dry continental climate and is dominated by shrublands. The west-central semiarid prairies and south-central semiarid prairies ecoregions are within the rain shadow of the Rocky Mountains and thus have relatively low precipitation, lower humidity, and colder continental temperatures. These areas are dominated by grassland and shrublands with forests in localized topographical settings. The more easterly mixed woods, temperate prairies, and southeastern plain ecoregions have relatively warmer and have more humid conditions during the growing season, influenced by fronts emanating from the Gulf of Mexico. Vegetation varies from grassland in the temperate prairies to deciduous forests in the mixed woods and southeastern plains. Across the entire study area, the strong latitudinal gradient in temperature is evident, while the gradient in precipitation is more longitudinal, going from drier to wetter as one moves from the western deserts to the central plains and on to the eastern ecoregions.

Available soil water deficit is common in the study region from the Rocky Mountains to the Mississippi Valley as a result of higher PET than precipitation (Adhikari and Hansen 2019). The region has a steep water-balance ecotone set up by moist mountains, dry rain-shadowed plains, and moist and humid Gulf of Mississippi-influenced prairie. The south-central semiarid prairies, temperate prairies, and southeastern plain ecoregions have become the center of the intensive agricultural activities depending upon irrigation facilities, rainfall, soil quality, and elevation (Adhikari and Hansen 2018). The drought-prone ecoregions support cattle grazing with localized agriculture in irrigated areas.

\section{b. Climate model selection}

We selected Multivariate Adaptive Constructive Analogs (MACA) datasets (Abatzoglou and Brown 2012) for climate variables because they provided biascorrected and spatially downscaled monthly average temperature, PPT, and PET data at 4-km spatial resolution. We evaluated eight GCMs, which had been found to better represent historical climate (19012014) in the NCUS (AdaptWest Project 2015; Wang et al. 2016). The three GCMs that we selected represent three divergent future climate projections based on the range in projected changes in annual temperature and precipitation in the region from a larger set of GCMs. The three GCMs and given climate projections are CNRM-CM5 (warm and wet), CCSM4 
TABLE 2. Ecoregions within the study area, listed from east to west, with their climate, topographical, and vegetation characteristics.

\begin{tabular}{|c|c|c|}
\hline Ecoregions & Area $\left(\mathrm{km}^{2}\right)$ & Characteristics \\
\hline Western cordillera 01 & 372384 & $\begin{array}{l}\text { High mountain regions covered by snow; mean temperature ranges from }-5^{\circ} \text { to } 8^{\circ} \mathrm{C} \text {; } \\
\text { annual precipitation ranges from } 118 \text { to } 2500 \mathrm{~cm} \text {; presence of glacial lakes; high } \\
\text { species diversity is present across the environmental gradients }\end{array}$ \\
\hline Cold deserts & 735493 & $\begin{array}{l}\text { Consists of plateaus interspersed with high-relief mountainous regions; continental } \\
\text { climate; summers are warm to hot; winters are cold and wet; temperatures range } \\
\text { from } 0^{\circ} \text { to } 8^{\circ} \mathrm{C} \text {; mean annual precipitation is } 130-500 \mathrm{~mm} \text { (Chambers et al. 2016); } \\
\text { lower mountains are drier and warmer and dominated by spruce, fir, and Douglas } \\
\text { fir; chaparral is dominated by pinyon-juniper and oak, which are common at lower } \\
\text { elevations }\end{array}$ \\
\hline Western cordillera 02 & 144057 & $\begin{array}{l}\text { Higher mountains including the Rockies; lower part is covered with grassland; high } \\
\text { altitudes are covered by snow; mean temperature ranges from }-5^{\circ} \text { to } 8^{\circ} \mathrm{C} \text {; annual } \\
\text { precipitation ranges from } 118 \text { to } 2500 \mathrm{~cm} \text {; the region is dominated by conifer } \\
\text { species }\end{array}$ \\
\hline West-central semiarid prairies & 619717 & $\begin{array}{l}\text { Includes the northeastern part of the Great Plains; grassy, flat-irregular high plains, } \\
\text { dunes, and badlands; dominated by rangelands; dry, midlatitude climate; hot } \\
\text { summers; cold winters; mean annual temperature ranges from } 3^{\circ} \text { to } 8.5^{\circ} \mathrm{C} \text {; annual } \\
\text { precipitation ranges from } 250 \text { to } 550 \mathrm{~mm} \text { (Chambers et al. 2016); covered by } \\
\text { mixed-grass prairie }\end{array}$ \\
\hline South-central semiarid prairies & 538435 & $\begin{array}{l}\text { Includes south -central part of the Great Plains; average temperature ranges from } 7^{\circ} \\
\text { to } 21^{\circ} \mathrm{C} \text {; annual precipitation ranges from } 250-750 \mathrm{~mm} \text {; warmer; dominated by } \\
\text { grassland and agriculture land; woody encroachment with juniper, mesquite, and } \\
\text { oak species is common }\end{array}$ \\
\hline Temperate prairies & 521958 & $\begin{array}{l}\text { Land covered with intensive cropland, forage for livestock, and extensive wetlands; } \\
\text { warm-hot season; temperature ranges from } 13^{\circ} \text { to } 17^{\circ} \mathrm{C} \text {; precipitation ranges from } \\
900 \text { to } 1100 \mathrm{~mm}\end{array}$ \\
\hline Mixed woods & 302393 & $\begin{array}{l}\text { Land covered with agriculture, forest, wetlands, and glacial lakes in the north; the } \\
\text { eastern part is dominated by nutrient poor soils, whereas south has fertile soils; } \\
\text { climate is warm and humid; warm summers and cold winters; temperature ranges } \\
\text { from }-3^{\circ} \text { to } 22^{\circ} \mathrm{C} \text {; annual precipitation ranges from } 720 \text { to } 1000 \mathrm{~mm} \text {; climate is } \\
\text { moderated by large water bodies (the Great Lakes). The ecoregion is dominated } \\
\text { by tree species such as Populus tremuloides, Abies balsamea, and Picea glauca }\end{array}$ \\
\hline Southeastern plain & 261334 & $\begin{array}{l}\text { Irregular plains and low hills; combination of forest, agriculture, and urban areas; } \\
\text { warmer and wetter environment is projected in the future; the dominant species of } \\
\text { the natural forests in this ecoregion are pine, hickory, and oak }\end{array}$ \\
\hline
\end{tabular}

(warm and dry), and IPSL-CM5A-MR (hot and dry) (Fig. 2) (for the definitions of these model acronyms, see https://www.ametsoc.org/PubsAcronymList). Data were analyzed for a historical (1980-2005) period and a future (2071-99) period under the RCP8.5 emissions scenario for each GCM. The RCP8.5 scenario represents an increase in the radiative forcing of $8.5 \mathrm{~W} \mathrm{~m}^{-2}$ by 2100 , which is suggested to be consistent with increases in atmospheric greenhouse gases at current rates for global greenhouse emissions (Moss et al. 2008). We used data for MaySeptember to represent growing-season conditions because this is the period most relevant to most native plant species and to agriculture. The effect of considering different period lengths for the growing season is expected to have relative smaller effects on these results. For the plains, we also expect relatively smaller differences in the growing season across the ecoregions within relatively narrow latitudinal extents of our study region.

\section{c. PET, MI, and dryland classes estimation}

In this study, we define PET to more broadly represent the evaporative demand term. In the MACA dataset, Penman PET was calculated using the PenmanMonteith FAO56 method that provides short-grass reference ET incorporating monthly solar radiation, relative humidity, air temperature, and wind speed (Allen et al. 1998). MI (=PPT/PET) was calculated with the PET values derived from Penman methods.

Drylands classes were estimated based on classes used by Feng and $\mathrm{Fu}$ (2013), encompassing dry subhumid $(0.50<\mathrm{MI}<0.65)$, semiarid $(0.2<\mathrm{MI}<0.5)$, arid $(0.05<\mathrm{MI}<0.2)$, and hyperarid $(\mathrm{MI}<0.05)$ regions.

\section{Results}

Substantial warming at the end of the century was projected for the selected climate projections. The intermediate CCSM4 model projected a mean 


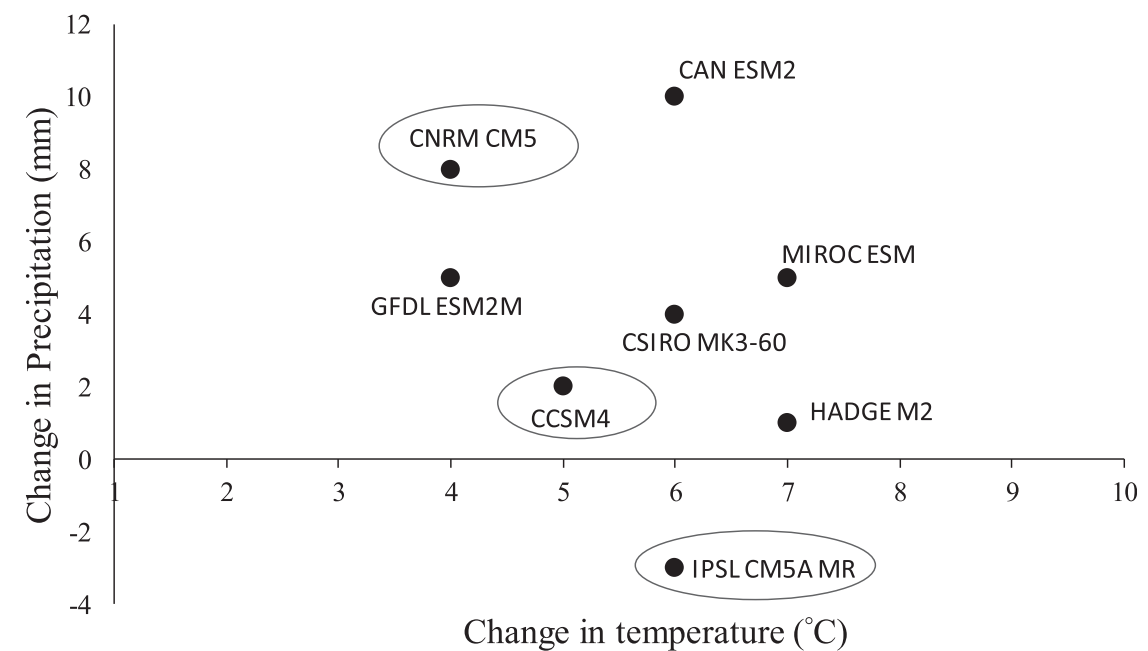

FIG. 2. A scatterplot of change in temperature and precipitation for different GCMs, including the three selected ones (circled). The three GCMs were selected from the eight GCMs shown in the plot on the basis of the range of projected change (2071-99 relative to 1980-2005) in temperature and precipitation and a relatively better representation of the historical climate of the study area and its vicinity.

growing-season temperature increase of $5.1^{\circ} \mathrm{C}(\mathrm{CNRM}$ $\mathrm{CM} 5 \rightarrow+3.5^{\circ} \mathrm{C}$; IPSL-CM5A-MR $\rightarrow+6.5^{\circ} \mathrm{C}$ ) (Fig. 3). The projected warming under CCSM4 was highest in the west-central semiarid prairies and western cordillera 01 ecoregions and lowest in the southern portion of the study area (Fig. 3). Precipitation was projected to decrease by $8 \%$ under CCSM4 (CNRM-CM $5 \rightarrow+14 \%$; IPSL-CM5A-MR $\rightarrow-17 \%$ ) (Fig. 3; Table 3). Spatial patterns of change under CCSM4 showed the largest relative decreases in PPT in the cold deserts and western cordillera 01 ecoregions and the least decreases in the three eastern ecoregions. The other two GCMs differed substantially from CCSM4 in spatial patterns of change in both temperature and precipitation (Fig. 3).

Historical PET was highest in the arid south-central semiarid prairies and cold deserts ecoregions and lowest in three relatively more humid ecoregions (Fig. 4). The historical PET was greatest in the south-central semiarid prairies and cold deserts ecoregions as compared with the three eastern ecoregions.

The projected change in PET was increased by $22 \%$ for the 2071-99 period under CCSM4 (CNRMCM5 $\rightarrow+10 \%$; IPSL-CM5A-MR $\rightarrow+23 \%$ ) (Fig. 4 ; Table 3). The change in PET under CCSM4 was relatively higher in the three eastern ecoregions (i.e., temperate prairies, mixed woods, and southeastern plains).

PET exceeded PPT during the growing season in the historical period across the study area, and thus MI was less than 1 under CCSM4 and IPSL-CM5A-MR. Average MI was 0.47 across the region, consistent with the higher PET estimated for the region. The spatial patterns of MI illustrate the strong east-west gradient in water balance across the study area (Fig. 4).

As expected on the basis of the projected increase in PET and changes in PPT, MI was projected to decrease by $25 \%$ under CCSM 4 (CNRM-CM $\rightarrow+4 \%$; IPSLCM5A-MR $\rightarrow-33 \%$ ) (Figs. 4 and 5; Table 3). On average MI was projected to decrease by $25 \%$, with rates of drying in excess of $30 \%$ in portions of the western cordillera 02 , cold deserts, west-central semiarid prairies, and temperate prairies ecoregions.

MI was projected to drop substantially across the study area under all climate projections. Maps of relative change in MI under CCSM4 indicate a significant decrease in available potential surface water was widespread across the study area with only portions of the cold deserts and west-central semiarid prairies having more moderate decreases (Fig. 5). However, important differences in MI among ecoregions can be observed that are explained by changes in input variables necessary to compute PET. The underlying patterns of the climate used to estimate PET using the Penman formulation explain these differences among ecoregions. The reduction in relative MI is more pronounced in the west-central semiarid region and both cordillera regions and also west of the cold deserts, and the least change is in a small part of the south-central semiarid prairies ecoregion. Temperate prairies, mixed woods, and the southeastern plains experienced a moderate change in MI (Fig. 5). Among GCMs, IPSL-CM5A-MR resulted in spatial patterns of drying similar to CCSM4 whereas CNRM-CM5 


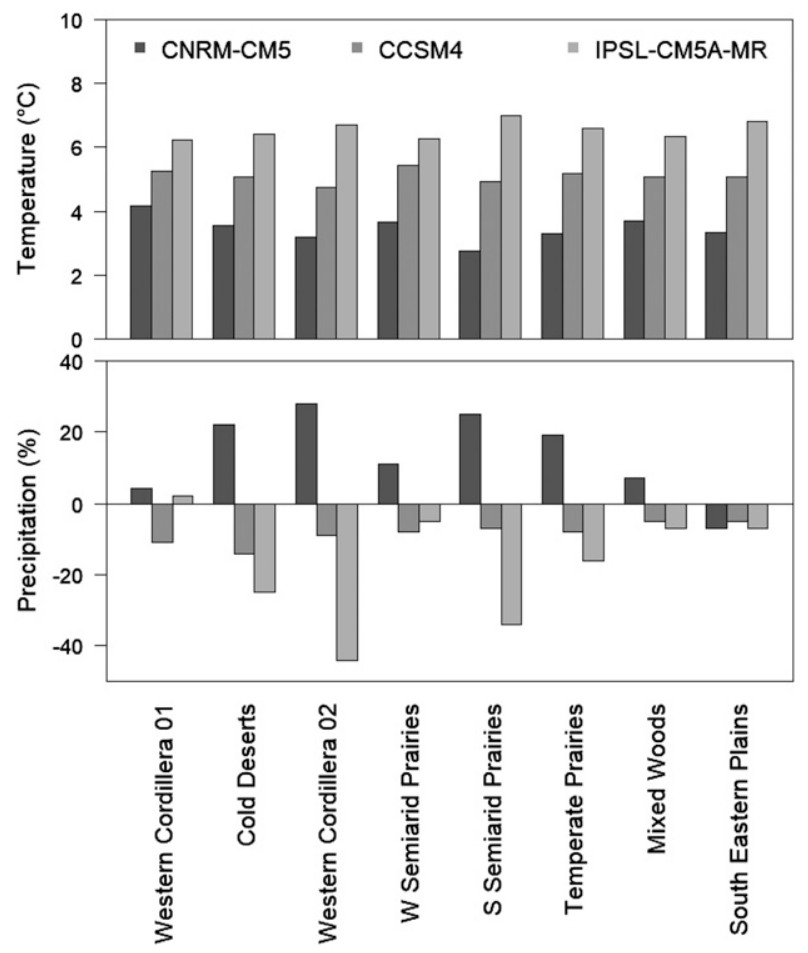

FIG. 3. Projected changes in growing-season temperature $\left({ }^{\circ} \mathrm{C}\right)$ and precipitation (\%) by 2071-99 relative to 1980-2005 across the eight ecoregions of the NCUS under three GCMs. (Abbreviation: $\mathrm{S}$ - south central; W-west central.)

resulted in much less drying in the eastern portion of the study area.

We also assessed changes in dryland classes based on MI values across the study region (Table 4; Figs. 6 and 7 ). Historically, the dryland occupied $\sim 95 \%$ of the study area under all climate projections including all of both cordillera, the cold deserts, west-central and south-central semiarid prairies, and northwest of the temperate prairies. As warming increased, the nondry class was projected to decrease under all projections by $-21 \%,-70 \%$, and $-70 \%$ for CNRM-CM 5 , CCSM 4 , and IPSL-CM5A-MR, respectively (Fig. 7). The decrease was observed across the southeastern plains and high mountains of the western ecoregions. Among the drylands, the dry subhumid class was projected to decrease by $-56 \%$ under CCSM4 (CNRM-CM $5 \rightarrow+5 \%$; IPSL-CM5A-MR $\rightarrow-88 \%$ ) across the temperate prairies, mixed woods, and southeastern prairies ecoregions. A $12 \%$ expansion of the semiarid class under CCSM4 (CNRM-CM5 $\rightarrow+6 \%$; IPSL-CM5A-MR $\rightarrow+16 \%$ ) was estimated across the mixed woods, temperate prairies, and southeastern prairies ecoregions and the high mountains of both cordilleras. The arid class was projected to increase by $+33 \%$ under CCSM 4 (CNRM-CM5 $\rightarrow$ $-8 \%$; IPSL-CM5A-MR $\rightarrow+53 \%)$. The expansion was
TABLE 3. Relative change (\%) between future (2071-2099) and historical (1980-2005) mean growing-season PPT, PET, and MI for different ecoregions and GCMs.

\begin{tabular}{|c|c|c|c|}
\hline Ecoregions & PPT & PET & MI \\
\hline \multicolumn{4}{|c|}{ CNRM-CM5 relative change (2005-99) } \\
\hline Western cordillera 01 & 3.77 & 15.43 & -10.76 \\
\hline Cold deserts & 21.61 & 7.12 & 13.59 \\
\hline Western cordillera 02 & 28.32 & 9.02 & 16.68 \\
\hline West-central semiarid prairies & 11.27 & 9.80 & 1.40 \\
\hline South-central semiarid prairies & 24.56 & 4.86 & 19.66 \\
\hline Temperate prairies & 18.73 & 8.25 & 10.32 \\
\hline Mixed woods & 6.92 & 12.58 & -5.08 \\
\hline Southeastern plain & -6.54 & 13.13 & -17.21 \\
\hline Avg & 13.58 & 10.02 & 3.58 \\
\hline \multicolumn{4}{|c|}{ CCSM4 relative change (2005-99) } \\
\hline Western cordillera 01 & -10.84 & 20.14 & -26.91 \\
\hline Cold deserts & -13.65 & 11.54 & -23.03 \\
\hline Western cordillera 02 & -9.23 & 16.69 & -23.22 \\
\hline West-central semiarid prairies & -7.98 & 19.97 & -23.40 \\
\hline South-central semiarid prairies & -7.06 & 23.71 & -25.12 \\
\hline Temperate prairies & -8.38 & 26.51 & -27.78 \\
\hline Mixed woods & -5.35 & 26.45 & -25.15 \\
\hline Southeastern plain & -4.86 & 27.15 & -25.19 \\
\hline Avg & -8.42 & 21.52 & -24.97 \\
\hline \multicolumn{4}{|c|}{ IPSL-CM5A-MR relative change (2005-99) } \\
\hline Western cordillera 01 & 1.65 & 22.58 & -18.04 \\
\hline Cold deserts & -24.74 & 16.07 & -34.71 \\
\hline Western cordillera 02 & -44.37 & 25.53 & -56.24 \\
\hline West-central semiarid prairies & -4.80 & 17.02 & -18.73 \\
\hline South-central semiarid prairies & -33.73 & 25.74 & -47.01 \\
\hline Temperate prairies & -16.21 & 26.47 & -33.66 \\
\hline Mixed woods & -7.00 & 26.81 & -26.59 \\
\hline Southeastern plain & -6.83 & 25.52 & -25.74 \\
\hline Avg & -17.00 & 23.22 & -32.59 \\
\hline
\end{tabular}

observed across the northeastern part of the west-central semiarid prairies, east of the south-central semiarid prairies, parts of both cordilleras, and the cold deserts ecoregions. The spatial extent of the hyperarid class was projected to change by $+135 \%$ under CCSM 4 (CNRMCM5 $\rightarrow-29 \%$; IPSL-CM5A-MR $\rightarrow 180 \%$ ), particularly across the cold deserts region. (Table 4; Fig. 7).

\section{Discussion}

The primary goal of this study was to evaluate projected changes in MI and the extent of drylands under the highest emission scenario (RCP8.5) using the newly available spatial data for Penman PET across the northcentral United States, a landscape with pronounced gradients in climate and topography. Our analysis is the first to use the robust formulation of PET (i.e., Penman) to project changes in moisture index and dryland extent with relatively fine spatial resolution under different future climate projections. We found that the ecosystems of the study region are highly exposed to 

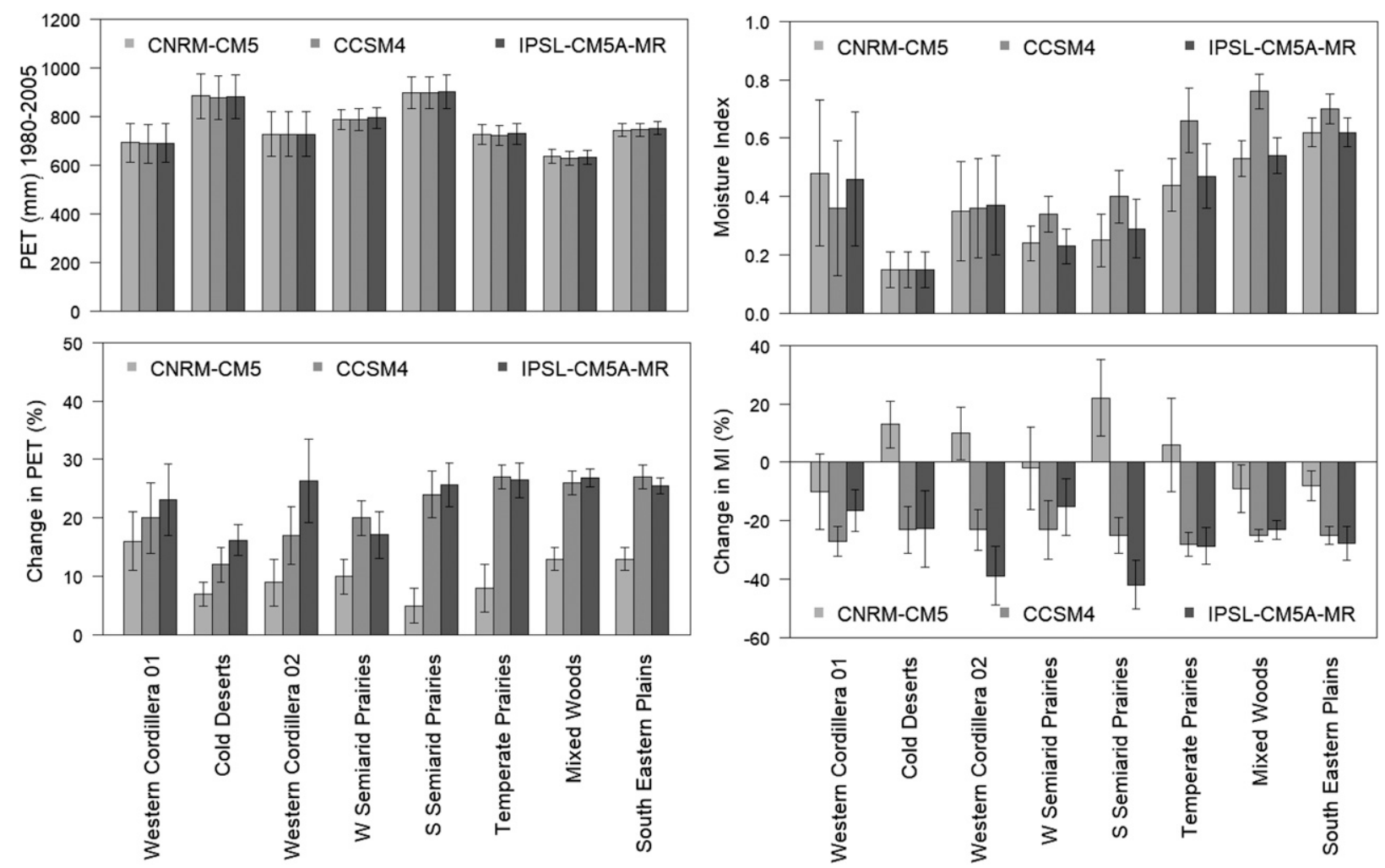

FIG. 4. Mean values of the historical growing-season (top left) PET and (top right) MI and percent change in (bottom left) PET and (bottom right) MI (from 1980-2005 to 2071-99) by ecoregions under three GCMs. Error bars represent the standard deviation.

climate change, with expansions of drylands under all climate projections despite the differences between models. In particular, the greatest expansion is seen under warmer and drier climate projections (i.e., IPSLCM5A-MR). We showed that an increase in temperature and PET and a decrease in precipitation caused drylands to become drier and warmer, with an increase in their spatial extent across the NCUS. This analysis is important because accurate projections of surface water availability through MI are needed to estimate hydrological, ecological, and agricultural response to climate change and to inform management for climate adaptation strategies.

Within our NCUS study area for the historical period, PET generally increased from north to south, reflecting the latitudinal patterns of growing-season temperature. The historical PET was higher in the eastern and southeastern ecoregions (except mixed wood) than in the relatively dry western ecoregions (except cold deserts). Penman PET formulation was influenced by change in vapor pressure deficit (VPD) in addition to temperature (Yao et al. 2014), and consequently large increases in PET were projected for the humid eastern portions of the study area. The Penman method considers solar radiation (including cloud cover effects), wind speed, and VPD in addition to temperature. Thus, controlling for temperature, the Penman PET is expected to be higher in relatively windy, dry, and higherradiation areas. Hence, Dewes et al. (2017) found Penman PET to be higher than a Thornthwaite-like metric, particularly in the Great Plains and southwestern United States where PET was strongly influenced by high wind and low relative humidity. Similar to previous studies (King et al. 2015), we found that PET was projected to increase substantially across our study area by the late twenty-first century under all three climate projections. However, relative change in PET did not follow the spatial pattern of temperature changes. The greatest increase in PET was in the eastern ecoregions and could be due to large projected increases in VPD.

Moisture index was projected to decrease across the study area under all climate projections. The projected decrease in MI was $25 \%$ on average, with rates of drying in excess of $30 \%$ largely across east-west gradients. The changes in MI were especially greater in the five more westerly ecoregions and less so in the three eastern ecoregions. Specifically, temperate prairies ecoregions, the west-central semiarid prairies, both cordillera, and the cold deserts showed a decrease in 

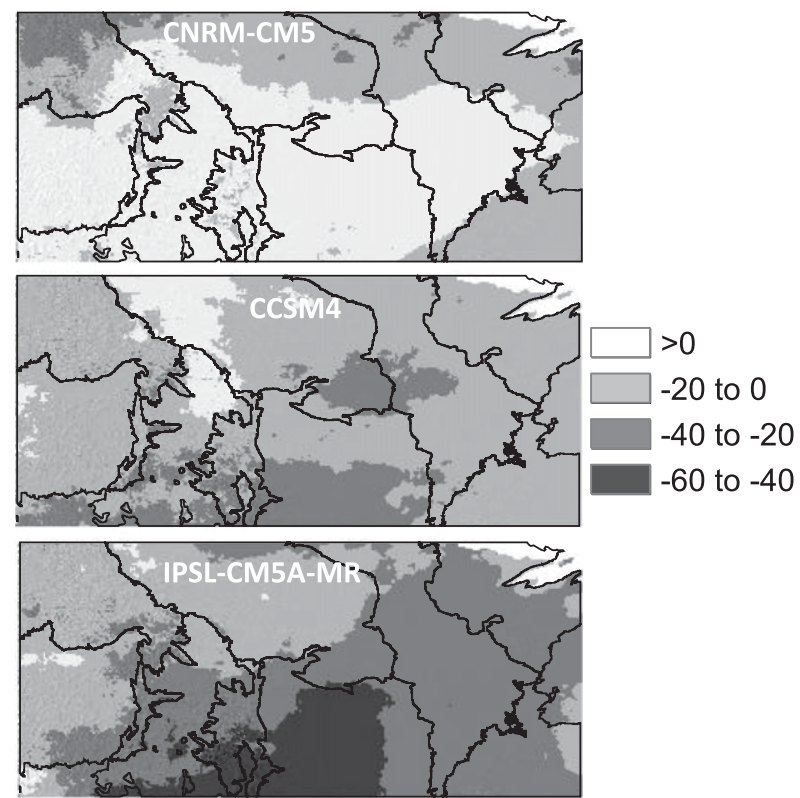

FIG. 5. Maps of percent change of MI (2071-99 relative to 19802005) for three climate projections across the study area.

MI, particularly due to a decrease in precipitation. These results are consistent with those of Dewes et al. (2017) who found more drying in the standardized precipitation evapotranspiration index. Even though PPT was projected to increase in western portions of the study area, this increase was not sufficient to offset the substantial increases on projected PET in these locations.

Projected changes in PET are responsible for the surface expansion of drylands (Milesi et al. 2010), as projected changes in temperature and precipitation enhance PET, particularly across the eastern ecoregions under warmer and drier conditions. This is because large increase in surface temperature and reduction in precipitation is responsible for a much-enhanced PET, particularly across the eastern ecoregions under a warmer and drier climate. Across the NCUS, Feng and Fu (2013) found model ensemble drying rates of $20 \%-40 \%$, generally similar to our findings. Using their classification scheme of dryland types, the proportion of our study area classified as semiarid, arid, and hyperarid ( $\mathrm{MI}<0.65)$ was projected to increase by $\sim 31 \%$ under relatively warmer projections represented by CCSM4 and IPSL-CM5A-MR. The findings of our study showed expansion of drylands associated with an increase in aridity resulting in potential aridification coupled with human modifications in this area (Reynolds et al. 2007; Tereshchenko et al. 2015; Adhikari and Hansen 2018). This is particularly true for the temperate prairies, west- and south-central semiarid prairies, and southeastern plains.

The projected changes in dryland classes are not homogeneous across the ecoregions. This is associated with the variation in projected increase in temperature and decrease in precipitation under warmer and drier climate projections. However, the study highlights significant shifts in dryland classes across the study region. Major expansion of arid and semiarid lands is projected across eastern ecoregions including both south-central and west-central semiarid prairies, temperate prairies, mixed woods, and southeastern plains ecoregions. These ecoregions experienced greater expansion as projected

TABLE 4. Spatial extent $\left(\mathrm{km}^{2}\right)$ and relative changes in the representative classes of dryland zones across the study area in the historical and future periods under three climate projections.

\begin{tabular}{|c|c|c|c|}
\hline & Area in $2005\left(\mathrm{~km}^{2}\right)$ & Area in $2099\left(\mathrm{~km}^{2}\right)$ & Percent change \\
\hline \multicolumn{4}{|c|}{ CNRM-CM5/drylands } \\
\hline Nondryland & 143076 & 113386.9 & -20.75 \\
\hline Dry subhumid $(0.5<\mathrm{MI}<0.65)$ & 746839.8 & 780975.6 & 4.57 \\
\hline Semiarid $(0.2<\mathrm{MI}<0.5)$ & 1628541 & 1719322 & 5.57 \\
\hline Arid $(0.05>\mathrm{MI}<0.2)$ & 1085676 & 997956.6 & -8.08 \\
\hline Hyperarid $(\mathrm{MI}<0.05)$ & 26089 & 18564 & -28.84 \\
\hline \multicolumn{4}{|c|}{ CCSM4/drylands } \\
\hline Nondryland & 166619 & 49325 & -70.40 \\
\hline Dry subhumid $(0.5<\mathrm{MI}<0.65)$ & 728991 & 317227 & -56.48 \\
\hline Semiarid $(0.2<\mathrm{MI}<0.5)$ & 1667475 & 1862899 & 11.72 \\
\hline Arid $(0.05>\mathrm{MI}<0.2)$ & 1021012 & 1362812 & 33.48 \\
\hline Hyperarid (MI < 0.05) & 16124.7 & 37958 & 135.40 \\
\hline \multicolumn{4}{|c|}{ IPSL-CM5A-MR/drylands } \\
\hline Nondryland & 140581 & 36001.5 & -74.39 \\
\hline Dry subhumid $(0.5<\mathrm{MI}<0.65)$ & 848349.5 & 99099.7 & -88.32 \\
\hline Semiarid $(0.2<\mathrm{MI}<0.5)$ & 1586413 & 1847014 & 16.43 \\
\hline Arid $(0.05>\mathrm{MI}<0.2)$ & 1028744 & 1574890 & 53.09 \\
\hline Hyperarid (MI < 0.05 ) & 26133.9 & 73216 & 180.16 \\
\hline
\end{tabular}



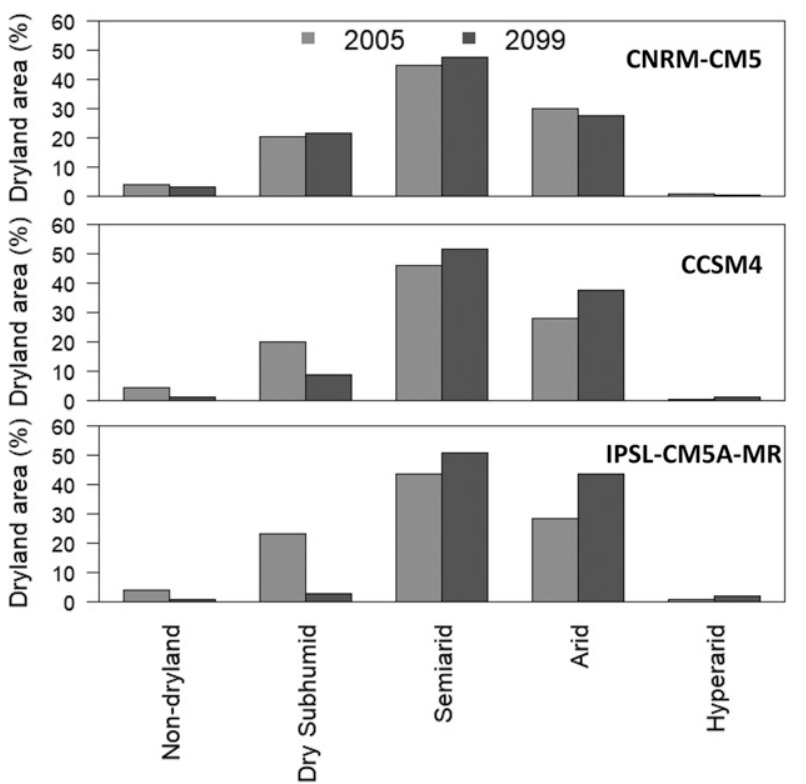

FIG. 6. Historical (1980-2005) and projected (2071-99) proportion of dryland area across the NCUS under three climate projections.

climate becomes warmer and drier (particularly under the CCSM4 and IPSL-CM5A-MR GCMs). The expansion of semiarid lands follows the similar spatial patterns and characters of arid lands, but more easterly. The dry subhumid land of the NCUS is projected to shrink across temperate prairies, plains, and mixed woods under drier climate. The arid land is projected to expand into regions historically occupied by semiarid and dry subhumid across western ecoregions (e.g., west and south semiarid prairies), whereas semiarid land is projected to expand in the regions historically characterized by dry subhumid and nondrylands of eastern ecoregions. However, expansion of hyperarid lands is shown in the area currently occupied by arid lands and is confined to the cold deserts ecoregion. The increase in aridification extent across this region is associated with the increase in PET and decrease in MI (Feng and $\mathrm{Fu}$ 2013). As much of the land across the NCUS is projected to convert to drylands, the entire region is susceptible to desertification under prolonged drought. Arid and semiarid regions are susceptible to prolonged drought resulting in land degradation, which increases risk of desertification (Reynolds et al. 2007).

Our findings showed that increase in PET plays a dominant role in the region projected to change from nonarid land and dry subhumid (temperate, mixed woods and southeastern plains ecoregions), whereas decrease in precipitation seems to be the major factors in the regions where shift occurs from semiarid to arid lands (e.g., west and south-central semiarid prairies).
However, ecoregions projected to have the greatest increase in PET and decrease in precipitation (e.g., western cordillera 02) also control expansion of semiarid lands to arid lands.

Our work shows that the projected changes in climate and water-balance variables are likely to exacerbate aridity across eight ecoregions of the NCUS Our results are consistent with the "dry get drier" paradigm (Held and Soden 2006). The nonarid and dry subhumid portions of the entire region is projected to change to arid or semiarid land. However, the extent of reduction in degree of moisture deficiency is ecoregion specific. With a strong east-west gradient, the projected decrease in MI was strongly pronounced in the westcentral prairies, both cordilleras, and the cold deserts ecoregions showing magnitudes that can be transferred into drought. The entire nonarid eastern regions (southeastern plains, mixed woods, and temperate prairies) have projected to become dry subhumid regions. The entire region is quickly approaching semiarid and arid conditions.

\section{a. Implications}

An important finding of this study is that all portions of the study area are likely to experience increased water stress during this century associated with greater increases in dryland areas. The potential consequences could be reduction in productivity and change in vegetation structure and ecosystem services questioning the sustainability of drylands across one of the most important crop production regions of the world. This is especially the case across the more arid ecoregions in the central and southwestern portions of the study area that encompass much of the productive agroecosystems of the U.S. northern Great Plains. Increasing land abandonment and a reduction in agriculture and livestock production across the Great Plains might be associated with increasing aridity under changing climate (Adhikari and Hansen 2018; Cline 2013; Harrington et al. 2007; Motha and Baier 2005; Izaurralde et al. 2003), which is consistent with expansion of drylands as shown by this study.

Increased aridity can have serious impacts on the natural vegetation of the western part of the study region. For the forested systems, water-balance factors such as PET and MI have long been recognized as waterlimiting factors affecting forest growth and survival across the region (McDowell et al. 2008). The enhanced droughts due to increasing PET in the future will likely expedite tree mortality in the arid-prone areas under the changing climate (Shaw et al. 2005; Huang et al. 2010). The PET increases as projected by climate models can significantly increase drought stress in the 

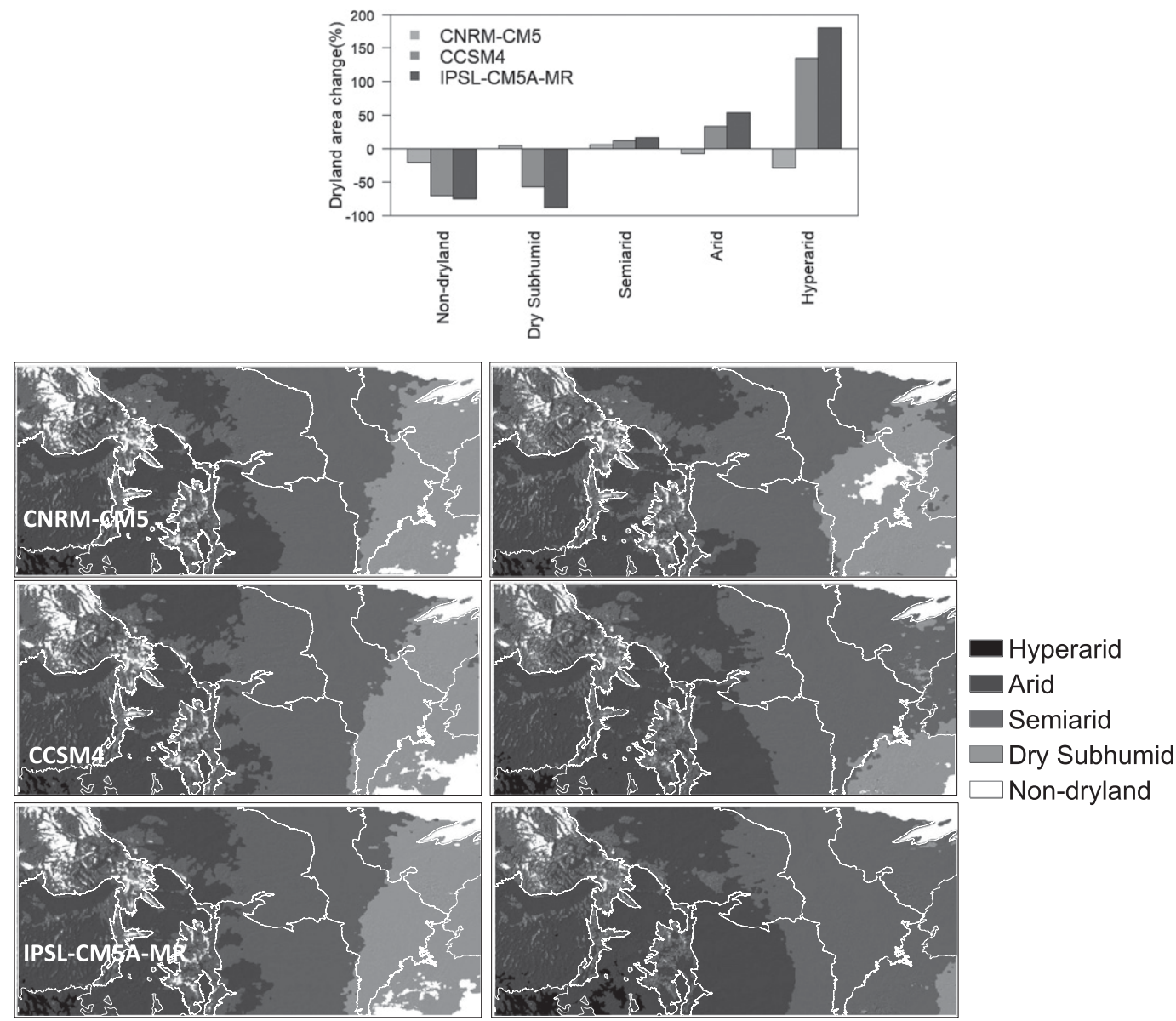

FIG. 7. (top) Percent change in dryland classes under three climate projections. The maps show spatial extents of dryland classes under three climate projections for (left) 1980-2005 and (right) 2071-99 as defined by MI across the NCUS.

region, which will likely to be more severe in the future than that of any megadrought in recent centuries (Breshears et al. 2005; Williams et al. 2013). A high correlation between drought stress and tree mortality reported by many studies suggests that the projected drought stress will be accompanied by intense forest decline (McDowell et al. 2008). Woody encroachment of grassland in southeastern prairies could be associated with increasing warming. Given the projected increase in higher atmospheric demands in the future, the study area is likely to experience such events more frequently (Lettenmaier et al. 2008).

The study region significantly contributes to the global economy through production of crops such as barley, cotton, olives, millet, sorghum, and wheat as well as livestock that includes cows, camels, goats, horses, and sheep (Darkoh 2003). Our study showed that water demands of various crops and vegetation of this region will increase with the decrease precipitation and increase PET. In general, the increase in aridity extent would lead to the decrease of crop water availability and agricultural productivity in highly arid-prone regions.

\section{b. Conclusions}

We examined projected changes in MI using finegrained spatial data for three different future climate projections across the north-central United States. We find that MI is decreasing across the region under all climate projections. Climate change, particularly elevated PET and decreasing MI, is increasing aridification of the north-central United States. However, the extent of projected aridification varies considerably among temperature and precipitation scenarios projected by GCMs. This study is the first in quantifying and evaluating the dryland categories across a landscape with complex gradients in climate. The study predicted the higher rate of change in PET and MI in the eastern ecoregions that are wetter and more humid. Projected change in precipitation was also high in the eastern ecoregions. Consequently, the reduction in MI 
was widespread across the study area, resulting in shifts in increase in distribution from moist dryland types to more arid dryland types. Our findings improve knowledge from earlier studies that the NCUS is warming and drying more under climate change, showing greater variation in spatial patterns among eight ecoregions. The specific spatial patterns of change in PET, MI, and drylands differ among GCMs, suggesting that scenario approaches are justified to identify climate adaptation strategies that are robust to uncertainty about future climate (e.g., Miller et al. 2015). We conclude the findings of our study may have significant relevance to ecological study, assessment of aridity, and hydrological budget across water-balance ecotones.

Acknowledgments. We greatly appreciate the thoughtful and constructive comments made by three anonymous reviewers to improve this paper. We acknowledge the funding and support that we received from the U.S. Department of Interior North Central Climate Adaptation Science Center (G14AP00181). The authors of this paper declare that they have no conflicts of interest. Each author has made a significant contribution to the paper: author Adhikari designed the study, developed methods, analyzed data, and wrote and reviewed the paper; author Hansen designed the study, developed methods, and wrote and reviewed the paper; and author Rangwala wrote the methods and reviewed the paper.

\section{REFERENCES}

Abatzoglou, J. T., and T. J. Brown, 2012: A comparison of statistical downscaling methods suited for wildfire applications. Int. J. Climatol., 32, 772-780, https://doi.org/10.1002/joc.2312.

AdaptWest Project, 2015: Gridded current and projected climate data for North America at $1 \mathrm{~km}$ resolution, interpolated using the ClimateNA v5.10 software. AdaptWest, accessed 8 October 2017, https://adaptwest.databasin.org/ pages/adaptwest-climatena.

Adhikari, A., and A. J. Hansen, 2018: Land use change and habitat fragmentation of wildland ecosystems of the north central United States. Landscape Urban Plann., 177, 196-216, https:// doi.org/10.1016/j.landurbplan.2018.04.014.

— , and - 2019: Climate and water balance change among public, private, and tribal lands within greater wildland ecosystems across north central USA. Climatic Change, 152, 551567, https://doi.org/10.1007/s10584-018-2351-7.

Adhikari, S., A. Adhikari, D. K. Weaver, A. Bekkerman, and F. D. Menalled, 2019: Impacts of agricultural management systems on biodiversity and ecosystem services of highly simplified dryland landscapes. Sustainability, 11, 3223, https:// doi.org/10.3390/su11113223.

Allen, R. G., L. S. Pereira, D. Raes, and M. Smith, 1998: Crop evapotranspiration-Guidelines for computing crop water requirements. FAO Irrigation and Drainage Paper 56, 300 pp., http://www.fao.org/3/X0490E/X0490E00.htm.
Bond, N. A., and K. A. Bumbaco, 2015: Summertime potential evapotranspiration in eastern Washington State. J. Appl. Meteor. Climatol., 54, 1090-1101, https://doi.org/10.1175/ JAMC-D-14-0228.1.

Breshears, D. D., and Coauthors, 2005: Regional vegetation dieoff in response to global-change-type drought. Proc. Natl. Acad. Sci. USA, 102, 15 144-15148, https://doi.org/10.1073/ pnas. 0505734102 .

Chambers, J. C., and Coauthors, 2016: Using resilience and resistance concepts to manage threats to sagebrush ecosystems, Gunnison sage-grouse, and greater sage-grouse in their eastern range: A strategic multi-scale approach. USDA Forest Service Rocky Mountain Research Station Gen. Tech. Rep. RMRS-GTR-356, 143 pp., https://www.fs.fed.us/ $\mathrm{rm} /$ pubs/rmrs_gtr356.pdf.

Clark, J. S., and Coauthors, 2016: The impacts of increasing drought on forest dynamics, structure, and biodiversity in the United States. Global Change Biol., 22, 2329-2352, https:// doi.org/10.1111/gcb.13160.

Cline, S. A., 2013: Land use and landscape change in the Rockies: Implications for mountain agriculture. The Future of Mountain Agriculture, S. Mann, Ed., Springer Geography, 5-19.

Danielson, J. J., and D. B. Gesch, 2011: Global multi-resolution terrain elevation data 2010 (GMTED2010). U.S. Geological Survey Open-File Rep. 2011-1073, 26 pp., https:// pubs.usgs.gov/of/2011/1073/pdf/of2011-1073.pdf.

Darkoh, M. B. K., 2003: Regional perspectives on agriculture and biodiversity in the drylands of Africa. J. Arid Environ., 54, 261-279, https://doi.org/10.1006/jare.2002.1089.

Dewes, C. F., I. Rangwala, J. J. Barsugli, M. T. Hobbins, and S. Kumar, 2017: Drought risk assessment under climate change is sensitive to methodological choices for the estimation of evaporative demand. PLOS ONE, 12, e0174045, https://doi.org/10.1371/journal.pone.0174045.

Feng, S., and Q. Fu, 2013: Expansion of global drylands under warming climate. Atmos. Chem. Phys., 13, 10 081-10 094, https:// doi.org/10.5194/acp-13-10081-2013.

Fisher, J. B., R. J. Whittaker, and Y. Malhi, 2011: ET come home: Potential evapotranspiration in geographical ecology. Global Ecol. Biogeogr., 20, 1-18, https://doi.org/10.1111/ j.1466-8238.2010.00578.x.

Hanson, R. L., 1991: Evapotranspiration and droughts. National Water Summary 1988-89-Hydrologic events and floods and droughts, U.S. Geological Survey Water Supply Paper 2375, 99-104, https://pubs.usgs.gov/wsp/2375/report.pdf.

Harrington, L., J. Harrington, and N. Kettle, 2007: Groundwater depletion and agricultural land use change in the High Plains: A case study from Wichita County, Kansas. Prof. Geogr., 59, 221-235, https://doi.org/10.1111/j.1467-9272.2007.00609.x.

Hatch, U., S. Jagtap, J. Jones, and M. Lamb, 1999: Potential effects of climate change on agricultural water use in the southeast U.S. J. Amer. Water Resour. Assoc., 35, 1551-1561, https:// doi.org/10.1111/j.1752-1688.1999.tb04237.x.

Held, I. M., and B. J. Soden, 2006: Robust responses of the hydrological cycle to global warming. J. Climate, 19, 5686-5699, https://doi.org/10.1175/JCLI3990.1.

Hobbins, M. T., A. Dai, M. L. Roderick, and G. D. Farquhar, 2008: Revisiting the parameterization of potential evaporation as a driver of long-term water balance trends. Geophys. Res. Lett., 35, L12403, https://doi.org/10.1029/2008GL033840.

, A. Wood, D. J. McEvoy, J. L. Huntington, C. Morton, M. Anderson, and C. Hain, 2016: The evaporative demand drought index. Part I: Linking drought evolution to variations 
in evaporative demand. J Hydrometeor., 17, 1745-1761, https://doi.org/10.1175/JHM-d-15-0121.1.

Huang, C., G. P. Asner, N. N. Barger, J. C. Neff, and M. L. Floyd, 2010: Regional aboveground live carbon losses due to drought-induced tree dieback in piñon-juniper ecosystems. Remote Sens. Environ., 114, 1471-1479, https://doi.org/10.1016/ j.rse.2010.02.003.

IPCC, 2013: Climate Change 2013: The Physical Science Basis. T. F. Stocker et al., Eds., Cambridge University Press, 1535 pp., https://doi.org/10.1017/CBO9781107415324.

Izaurralde, R. C., N. J. Rosenberg, A. Brown, and A. M. Thomson, 2003: Integrated assessment of Hadley Center (HadCM2) climate-change impacts on agricultural productivity and irrigation water supply in the conterminous United States: Part II. Regional agricultural production in 2030 and 2095. Agric. Meteor., 117, 97-122, https://doi.org/10.1016/S0168-1923(03) 00024-8.

King, D. A., B. M. Dominique, A. J. Symstad, K. Ferschweiler, and M. Hobbins, 2015: Estimation of potential evapotranspiration from extraterrestrial radiation, air temperature and humidity to assess future climate change effects on the vegetation of the Northern Great Plains, USA. Ecol. Modell., 297, 86-97, https://doi.org/10.1016/j.ecolmodel.2014.10.037.

Lettenmaier, D., D. Major, L. Poff, and S. Running, 2008: Water resources. The Effects of Climate Change on Agriculture, Land Resources, Water Resources and Biodiversity in the United States, P. Backlund et al., Eds., Synthesis and Assessment Product 4.3. U.S. Department of Agriculture, 121-150, https:// www.fs.fed.us/rm/pubs_other/rmrs_2008_backlund_p003.pdf.

McDowell, N. G., and Coauthors, 2008: Mechanisms of plant survival and mortality during drought: Why do some plants survive while others succumb to drought? New Phytol., 178, 719-739, https://doi.org/10.1111/j.1469-8137.2008.02436.x.

McKenney, M. S., and N. J. Rosenberg, 1993: Sensitivity of some potential evapotranspiration estimation methods to climate change. Agric. For. Meteor., 64, 81-110, https://doi.org/ 10.1016/0168-1923(93)90095-Y.

Milesi, C., and Coauthors, 2010: Decadal variations in NDVI and food production in India. Remote Sens., 2, 758-776, https:// doi.org/10.3390/rs2030758.

Millennium Ecosystem Assessment, 2005: Ecosystems and $\mathrm{Hu}$ man Well-Being: Desertification Synthesis. World Resources Institute, $26 \mathrm{pp}$., https://www.millenniumassessment.org/ documents/document.355.aspx.pdf.

Miller, B.W., L. Frid, T. Chang, N. Piekielek, A. J. Hansen, and J. T. Morisette, 2015: Combining state-and-transition simulations and species distribution models to anticipate the effects of climate change. AIMS Environ. Sci., 2, 400-426, https:// doi.org/10.3934/environsci.2015.2.400.

Monteith, J. L., 1965: Evaporation and environment. The state and movement of water in living organism. Proceedings of the Society for Experimental Biology, Symposium No. 19, Cambridge University Press, 205-234.

Moss, R. H., and Coauthors, 2008: Towards new scenarios for analysis of emissions, climate change, impacts, and response strategies: Technical summary. Intergovernmental Panel on Climate Change Expert Meeting Rep., 25 pp., https:// www.ipcc.ch/site/assets/uploads/2018/05/expert-meeting-tsscenarios-1-1.pdf.

Motha, R. P., and W. Baier, 2005: Impacts of present and future climate change and climate variability on agriculture in the temperate regions: North America. Climatic Change, 70, 137 164, https://doi.org/10.1007/s10584-005-5940-1.

Penman, H. L., 1948: Natural evaporation from open water, bare soil and grass. J. Proc. Roy. Soc. London, 193A, 120-145, https://doi.org/10.1098/rspa.1948.0037.

Priestley, C. H. B., and R. J. Taylor, 1972: On the assessment of surface heat flux and evaporation using large-scale parameters. Mon. Wea. Rev., 100, 81-92, https://doi.org/10.1175/ 1520-0493(1972)100<0081:OTAOSH>2.3.CO;2.

Reynolds, J. F., and Coauthors, 2007: Global desertification: Building a science for dryland development. Science, 316, 847-851, https://doi.org/10.1126/science.1131634.

Rind, D., R. Goldberg, J. Hansen, C. Rosenzweig, and R. Ruedy, 1990: Potential evapotranspiration and the likelihood of future drought. J. Geophys. Res., 95, 9983-10004, https://doi.org/ 10.1029/JD095iD07p09983.

Shaw, J. D., B. E. Steed, and L. T. DeBlander, 2005: Forest Inventory and Analysis (FIA) annual inventory answers the question: What is happening to pinyon-juniper woodlands? J. For., 103, 280-285.

Tereshchenko, I., A. N. Zolotokrylin, E. A. Cherenkova, C. O. Monzon, L. Brito-Castillo, and T. B. Titkova, 2015: Changes in aridity across Mexico in the second half of the century. J. Appl. Meteor. Climatol., 54, 2047-2062, https://doi.org/ 10.1175/JAMC-D-14-0207.1.

Thornthwaite, C. W., 1948: An approach toward a rational classification of climate. Geogr. Rev., 38, 55-94, https://doi.org/ 10.2307/210739.

Turc, L., 1961: Evaluation des besoins en eau d'irrigation, evapotranspiration potentielle, formulation simplifié et mise à jour. Ann. Agron., 12, 13-49.

UNCCD, 1994: United Nations convention to combat desertification in those countries experiencing serious drought and desertification, particularly in Africa. United Nations Treaty Series, Vol. 1954, 3, https://treaties.un.org/pages/ViewDetails.aspx? $\mathrm{src}=$ TREATY\&mtdsg no $=$ XXVII-10\&chapter $=27 \&$ clang $=\_$en.

van der Schrier, G., P. D. Jones, and K. R. Briffa, 2011: The sensitivity of the PDSI to the Thornthwaite and PenmanMonteith parameterizations for potential evapotranspiration. J. Geophys. Res., 116, D03106, https://doi.org/10.1029/ 2010JD015001.

Vogt, J. V., U. Safriel, G. Von Maltitz, Y. Sokona, R. Zougmore, G. Bastin, and J. Hill, 2011: Monitoring and assessment of land degradation and desertification: Towards new conceptual and integrated approaches. Land Degrad. Dev., 22, 150-165, https://doi.org/10.1002/ldr.1075.

Wang, T., A. Hamann, D. Spittlehouse, and C. Carroll, 2016: Locally downscaled and spatially customizable climate data for historical and future periods for North America. PLoS One, 11 (6), e0156720, https://doi.org/10.1371/journal.pone.0156720.

Williams, A. P., and Coauthors, 2013: Temperature as a potent driver of regional forest drought stress and tree mortality. Nat. Climate Change, 3, 292-297, https://doi.org/10.1038/ nclimate1693.

Yao, Y., S. Zhao, Y. Zhang, K. Jia, and M. Liu, 2014: Spatial and decadal variations in potential evapotranspiration of China based on reanalysis datasets during 1982-2010. Atmosphere, 5, 737-754, https://doi.org/10.3390/atmos5040737.

Zarch, M. A. A., B. Sivakumar, H. Malekinezhad, and A. Sharma, 2017: Future aridity under conditions of global climate change. J. Hydrol., 554, 451-469, https://doi.org/10.1016/ j.jhydrol.2017.08.043. 